\title{
ASSESSMENT OF STERNAL VASCULARITY WITH SINGLE PHOTON EMISSION COMPUTED TOMOGRAPHY AFTER HARVESTING OF THE INTERNAL THORACIC ARTERY
}

Amram J. Cohen, MD

Judith Lockman, $\mathrm{MD}^{\mathrm{b}}$

Mordechai Lorberboym, $\mathrm{MD}^{\mathrm{c}}$

Othman Bder, MD

Nadav Cohen ${ }^{\mathrm{a}}$

Benjamin Medalion, $\mathrm{MD}^{\mathrm{a}}$

Arie Schachner, MD
Objective: This study prospectively evaluates the effect on sternal vascularity of harvesting the left internal thoracic artery. Methods: Twentyfour consecutive patients undergoing primary coronary artery bypass grafting were studied. One patient's procedure was altered during the operation, and he was eliminated from the study. The patients were prospectively randomized to receive a skeletonized internal thoracic artery (group I, $\mathbf{n}=11$ ) or a pedicled internal thoracic artery (group II, n = 12) graft. Each patient underwent a preoperative technetium 99 methylene diphosphonate bone scan using single photon emission computed tomography. The ratio of the mean counts per pixel on the left side of the sternum was compared with the mean counts per pixel on the right side. Postoperatively, all patients had a second scan, and sternal uptake was compared with the preoperative uptake. Results: No significant differences in preoperative and operative variables were observed between the groups. A statistically significant reduction in blood flow to the left side of the sternum was shown postoperatively in group II compared with group I $(0.61 \pm 0.11$ vs $0.85 \pm 0.09 ; P<.001)$. Multivariable logistic regression analysis of preoperative and operative variables revealed only a pedicled left internal thoracic artery to be associated with a $20 \%$ or more reduction in left-to-right sternal activity ratio (odds ratio, 100; $70 \%$ confidence limits, $22-465 ; P=.002)$. Conclusion: A pedicled left internal thoracic artery graft to the left anterior descending artery reduces blood flow to the left side of the sternum during the acute postoperative period. This does not occur when the left internal thoracic artery is skeletonized. (J Thorac Cardiovasc Surg 1999;118:496-502)
$\mathrm{T}$ he excellence of the left internal thoracic artery (ITA) as a graft to the left anterior descending artery during coronary artery bypass grafting (CABG) is clearly established. ${ }^{1,2}$ Whether the left ITA should be harvested as a pedicled graft or as a skeletonized artery is unknown. No information has been published concerning the difference in long-term patency of these 2 types of grafts. There is, however, some experimental and clinical evidence suggesting that a skeletonized

From the Departments of Cardiovascular Surgery, ${ }^{\mathrm{a}}$ Radiology, ${ }^{\mathrm{b}}$ and Nuclear Medicine Institute, ${ }^{c}$ Edith Wolfson Medical Center, Holon, Israel (affiliated with Sackler Faculty of Medicine, Tel Aviv University, Ramat Aviv).

Received for publication Dec 18, 1998; revisions requested Feb 24, 1999; revisions received May 24, 1999; accepted for publication June 3, 1999.

Address for reprints: Amram Cohen, MD, Department of Cardiovascular Surgery, Wolfson Medical Center, Holon 58100, Israel.

Copyright $\odot 1999$ by Mosby, Inc.

$0022-5223 / 99 \$ 8.00+0 \quad \mathbf{1 2 / 1 / 1 0 0 4 0 5}$ graft will reduce postoperative mediastinal infection, reduce acute postoperative sternal ischemia, and reduce acute postoperative morbidity. ${ }^{3-6}$ The purpose of this study was to prospectively evaluate the effect of the type of ITA harvest on sternal vascularity and the postoperative course.

\section{Patients and methods}

Twenty-four consecutive patients undergoing elective primary CABG were chosen for the study. The study was approved by our institutional review board, and all patients gave informed consent for the study. The patients were prospectively randomized to receive either a skeletonized left ITA or a pedicled left ITA graft either to the left anterior descending artery individually or as a left anterior descending/diagonal sequential graft. One patient, randomized to the skeletonized group, received a right ITA as well, because of intraoperative technical considerations, and was excluded from the study. As a result, the skeletonized group (group I) comprised 11 patients and the pedicled group (group II), 12 patients. 
Table I. Preoperative patient characteristics

\begin{tabular}{lccc}
\hline Variables & $\begin{array}{c}\text { Skeletonized } \\
\text { group }(n=11)\end{array}$ & $\begin{array}{c}\text { Pedicled } \\
\text { group }(n=12)\end{array}$ & P value \\
\hline Sex (male/female) & $8 / 3$ & 12 & .09 \\
Age (y) & $63 \pm 8.9$ & $67 \pm 8.7$ & .3 \\
Diabetes mellitus & 6 & 4 & .64 \\
COPD & 4 & 2 & .64 \\
Unstable angina & 7 & 8 & .67 \\
Previous MI & 4 & 8 & .06 \\
Creatinine (mg/dL) & $1.14 \pm 0.16$ & $1.2 \pm 0.25$ & .45 \\
Ventricular ejection & $54 \pm 8.4$ & $53 \pm 12.1$ & .83 \\
fraction $(\%)^{*}$ & & & \\
\hline
\end{tabular}

COPD, Chronic obstructive pulmonary disease; $M I$, myocardial infarction.

*Values are mean \pm standard deviation.

Preoperative demographic data, cardiac risk factors, and subsystems were evaluated for each patient, as were intraoperative variables. Operative data collected included bypass time, crossclamp time, and number of grafts. The postoperative course, including intubation time, intensive care unit stay, and hospital stay were recorded.

Before the operation, each patient underwent a bone scan using single photon emission computed tomography (SPECT) to evaluate the baseline sternal vascularity. A single-head gamma camera (Apex SP-4, Elscint, Haifa, Israel) equipped with a low-energy high-resolution collimator (APC-45) was used. Imaging began 3 hours after intravenous injection of $740 \mathrm{MBq}(20 \mathrm{mCi})$ of technetium 99 methylene diphosphonate (Tc-99-m-MDP; Soreq Pharmaceutical Co, Yavneh, Israel). Sixty projections of 20 seconds each, over a $180^{\circ}$ anterior arc, were acquired from the right lateral position to the left lateral position in a $64 \times 64$ matrix at $3^{\circ}$ angular steps. Transaxial, coronal, and sagittal slices 2 pixels thick were reconstructed with a $3 \mathrm{rd}$ order Metz filter set to $10 \mathrm{~mm}$ full width at half maximum (FWHM). Only the coronal sections were used for quantitative analysis. A repeat bone SPECT was performed 4 to 9 days after the operation with the same parameters of camera distance and bed height used for each patient.

The quantitative analysis was performed by a specialist in nuclear medicine (M.L.) blinded to the patients' therapy. A manual region of interest (ROI) was drawn on the right half of the sternum. The medial border was placed at the center of the sternum, and the lateral border delineated the sharp interface between sternal activity and low background activity. A mirror image of an equivalent ROI, with minor differences in the number of pixels (see Table III), was placed on the opposite side of the sternum. The mean number of counts per pixel was calculated for each ROI and compared statistically. The preoperative and postoperative areas (pixels) in each group on the left and right sides of the sternum were compared to assess whether there were significant differences in the areas evaluated.

Postoperatively, the patients were evaluated for acute complications, including intubation time, intensive care unit stay, and hospital stay. The patients returned for a follow-up visit
Table II. Operative data

\begin{tabular}{lccc}
\hline Variables & $\begin{array}{c}\text { Skeletonized } \\
\text { group }(n=11)\end{array}$ & $\begin{array}{c}\text { Pedicled } \\
\text { group }(n=12)\end{array}$ & P value \\
\hline Radial artery & 10 & 8 & \\
CPB time (min) & $130 \pm 26.9$ & $115 \pm 36.14$ & .25 \\
Crossclamp time (min)* & $75 \pm 19.7$ & $70 \pm 20$ & .6 \\
\hline
\end{tabular}

$C P B$, Cardiopulmonary bypass.

*Values are mean \pm standard deviation.

between 1 and 6 months later. At that time, a general evaluation, as well as a detailed evaluation of sternal pain, was recorded. The evaluation of sternal pain included a questionnaire that noted characteristics of the pain. This included pain with breathing, pain on touch, numbness, and tingling.

Operative technique. The ITA was harvested with the aid of cautery on identical settings in each case and sharp dissection in both groups. Skeletonized ITAs were harvested by mobilizing the artery only, leaving both veins on the chest wall. Pedicled ITAs were harvested with a $2-\mathrm{cm}$ pedicle, including muscle and fascia. Individual branches of the ITA were individually controlled with clips. An attempt was made to leave the left pleura closed in all cases. Hemostasis of the ITA bed was performed with cautery. The sternum was closed with individual steel wires.

Statistical analysis. Cases were compared between the 2 groups with the use of the Student $t$ test. Categoric variables were tested by means of the $\chi^{2}$ test or Fisher's exact test, when appropriate. Logistic regression was used to explore the preoperative and operative risk factors for a $20 \%$ reduction in sternal uptake on the left side of the sternum in the postoperative scans.

\section{Results}

The demographic and preoperative variables of the 2 groups are shown in Table I. The study included 3 women and 20 men, with a mean age of $63 \pm 8.9$ and $67 \pm 8.7$ years in groups I and II, respectively. No significant differences in the preoperative variables were observed between the 2 groups. Table II shows the operative variables. Again, no significant differences were detected between the groups.

The baseline bone SPECT before the operation showed no significant difference between left-to-right sternal activity ratio comparing the pedicled and skeletonized groups (Table III). No significant difference was observed in the area evaluated between the left and right sides of the sternum in either group (Table III). A second bone scan was performed $6.2 \pm 2.5$ days after the operation in group I and $5.41 \pm 1.08$ days after the operation in group II $(P=.35)$. In the postoperative scans, a statistically significant reduction in left-to-right sternal activity ratio $(P<.001)$ was observed in patients with pedicled grafts (Table I). Fig 
Table III. Sternal uptake data: group I

\begin{tabular}{|c|c|c|c|c|c|c|}
\hline $\begin{array}{l}\text { Patient } \\
\text { No. }\end{array}$ & $\begin{array}{l}\text { Sternal } \\
\text { side }\end{array}$ & $\begin{array}{c}\text { Preoperative } \\
\text { counts/pixel }\end{array}$ & $\begin{array}{c}\text { Preoperative } \\
\text { ratio (left/right) }\end{array}$ & $\begin{array}{c}\text { Postoperative } \\
\text { counts/pixel }\end{array}$ & $\begin{array}{l}\text { Postoperative } \\
\text { ratio (left/right) }\end{array}$ & $\mathrm{P}$ value \\
\hline 1 & $\begin{array}{l}\text { Left } \\
\text { Right }\end{array}$ & $\begin{array}{l}6493 / 90=72 \\
6850 / 89=77\end{array}$ & 0.93 & $\begin{array}{l}3913 / 87=45 \\
4250 / 85=50\end{array}$ & 0.90 & \\
\hline 2 & $\begin{array}{l}\text { Left } \\
\text { Right }\end{array}$ & $\begin{array}{l}2304 / 48=48 \\
2640 / 44=60\end{array}$ & 0.80 & $\begin{array}{l}1624 / 56=22 \\
2073 / 62=33.4\end{array}$ & 0.86 & \\
\hline 3 & $\begin{array}{l}\text { Left } \\
\text { Right }\end{array}$ & $\begin{array}{l}2449 / 48=51 \\
3594 / 48=75\end{array}$ & 0.68 & $\begin{array}{l}3146 / 62=50.7 \\
3349.6 / 53=63.2\end{array}$ & 0.79 & \\
\hline 5 & $\begin{array}{l}\text { Left } \\
\text { Right }\end{array}$ & $\begin{array}{l}5448 / 63=86.5 \\
5614 / 64=87.7\end{array}$ & 0.98 & $\begin{array}{l}1819 / 46=40 \\
1845 / 41=45\end{array}$ & 0.88 & \\
\hline 9 & $\begin{array}{l}\text { Left } \\
\text { Right }\end{array}$ & $\begin{array}{l}3312 / 49=67.6 \\
3630 / 51=71.1\end{array}$ & 0.95 & $\begin{array}{l}5449 / 63=86.5 \\
6383 / 65=98.2\end{array}$ & 0.88 & \\
\hline 12 & $\begin{array}{l}\text { Left } \\
\text { Right }\end{array}$ & $\begin{array}{l}1925 / 48=40.1 \\
1859 / 44=42.3\end{array}$ & 0.94 & $\begin{array}{l}1822 / 48=38 \\
2122 / 49=43.3\end{array}$ & 87.7 & \\
\hline 14 & $\begin{array}{l}\text { Left } \\
\text { Right }\end{array}$ & $\begin{array}{l}3247 / 64=50.7 \\
4225 / 65=65\end{array}$ & 0.78 & $\begin{array}{l}3281 / 57=57.5 \\
4126 / 61=67.6\end{array}$ & 0.85 & \\
\hline 18 & $\begin{array}{l}\text { Left } \\
\text { Right }\end{array}$ & $\begin{array}{l}3718 / 57=65.2 \\
4645 / 57=81.5\end{array}$ & 0.80 & $\begin{array}{l}2821 / 53=53.2 \\
3535 / 52=68\end{array}$ & 0.77 & \\
\hline 20 & $\begin{array}{l}\text { Left } \\
\text { Right }\end{array}$ & $\begin{array}{l}4771 / 81=58.9 \\
4287 / 68=63.0\end{array}$ & 0.93 & $\begin{array}{l}7983 / 90=88.7 \\
8510 / 87=98\end{array}$ & 0.90 & \\
\hline 22 & $\begin{array}{l}\text { Left } \\
\text { Right }\end{array}$ & $\begin{array}{l}4487 / 81=55.3 \\
4622 / 71=65.1\end{array}$ & 0.85 & $\begin{array}{l}5299 / 75=70.6 \\
5958.4 / 76=78.4\end{array}$ & 0.90 & \\
\hline 23 & $\begin{array}{l}\text { Left } \\
\text { Right }\end{array}$ & $\begin{array}{l}4152 / 86=48.3 \\
4015 / 76=52.8\end{array}$ & 0.91 & $\begin{array}{l}1583.4 / 78=20.3 \\
2005 / 74=27.0\end{array}$ & 0.75 & \\
\hline $\begin{array}{l}\text { Mean ratio of } \\
\text { sternal activity }\end{array}$ & & & $0.87 \pm 0.14 *$ & & $0.85 \pm 0.09^{*}$ & .56 \\
\hline
\end{tabular}

Values are mean \pm standard deviation.

Table III. Cont'd. Sternal uptake data: group II

\begin{tabular}{|c|c|c|c|c|c|c|}
\hline $\begin{array}{l}\text { Patient } \\
\text { No. }\end{array}$ & $\begin{array}{l}\text { Sternal } \\
\text { side }\end{array}$ & $\begin{array}{l}\text { Preoperative } \\
\text { counts/pixel }\end{array}$ & $\begin{array}{c}\text { Preoperative } \\
\text { ratio (left/right) }\end{array}$ & $\begin{array}{c}\text { Postoperative } \\
\text { counts/pixel }\end{array}$ & $\begin{array}{c}\text { Postoperative } \\
\text { ratio (left/right) }\end{array}$ & $\mathrm{P}$ value \\
\hline \multirow[t]{2}{*}{4} & Left & $4183 / 55=76.1$ & 0.90 & $3663 / 75=48.8$ & 0.75 & \\
\hline & Right & $4872 / 58=84$ & & $4904 / 76=64.5$ & & \\
\hline \multirow[t]{2}{*}{6} & Left & $3628 / 71=52$ & 0.89 & $7682 / 106=72.5$ & 0.75 & \\
\hline & Right & $4276 / 74=57.8$ & & $11,038 / 115=96$ & & \\
\hline \multirow[t]{2}{*}{7} & Left & $6313 / 53=119.1$ & 0.86 & $2008 / 45=44.6$ & 0.65 & \\
\hline & Right & $6465 / 47=137.5$ & & $2755 / 40=68.8$ & & \\
\hline \multirow[t]{2}{*}{8} & Left & $3839 / 46=83.4$ & 0.97 & $3421 / 74=46.2$ & 0.73 & \\
\hline & Right & $3500 / 41=85.4$ & & $4804 / 76=63.2$ & & \\
\hline \multirow[t]{2}{*}{10} & Left & $4284 / 58=73.9$ & 0.91 & $2839 / 46=61.7$ & 0.72 & \\
\hline & Right & $4790 / 59=81.2$ & & $3500 / 41=85.4$ & & \\
\hline \multirow[t]{2}{*}{11} & Left & $3521 / 51=69$ & 0.97 & $1575 / 47=33.5$ & 0.63 & \\
\hline & Right & $3831 / 54=71$ & & $2817 / 53=53.1$ & & \\
\hline \multirow[t]{2}{*}{13} & Left & $3630 / 51=71$ & 0.95 & $2983 / 61=48.9$ & 0.61 & \\
\hline & Right & $3321 / 49=68$ & & $4055 / 51=79.5$ & & \\
\hline \multirow[t]{2}{*}{15} & Left & $2680 / 55=48.7$ & 0.92 & $1018 / 52=19.5$ & 0.38 & \\
\hline & Right & $2568 / 57=45$ & & $2665 / 53=50.3$ & & \\
\hline \multirow[t]{2}{*}{16} & Left & $4316 / 60=72$ & 0.943 & $3016 / 79=38.1$ & 0.52 & \\
\hline & Right & $4272 / 56=76.3$ & & $6461 / 89=72.6$ & & \\
\hline \multirow[t]{2}{*}{17} & Left & $1061 / 51=20.8$ & 0.86 & $1062 / 48=22.1$ & 0.38 & \\
\hline & Right & $1106 / 46=24$ & & $2635 / 45=58.5$ & & \\
\hline \multirow[t]{2}{*}{19} & Left & $5745 / 85=67.5$ & 0.88 & $4181 / 88=47.5$ & 0.61 & \\
\hline & Right & $5725 / 75=76.6$ & & $7335 / 94=78$ & & \\
\hline \multirow[t]{2}{*}{21} & Left & $2723 / 60=45.3$ & 0.87 & $3476 / 78=44.6$ & 69.5 & \\
\hline & Right & $3153 / 61=51.7$ & & $5068 / 79=64.1$ & & \\
\hline $\begin{array}{r}\text { Mean ratio of } \\
\text { sternal ratio }\end{array}$ & & & $0.91 \pm 0.09^{*}$ & & $0.61 \pm 0.1^{*}$ & .001 \\
\hline
\end{tabular}



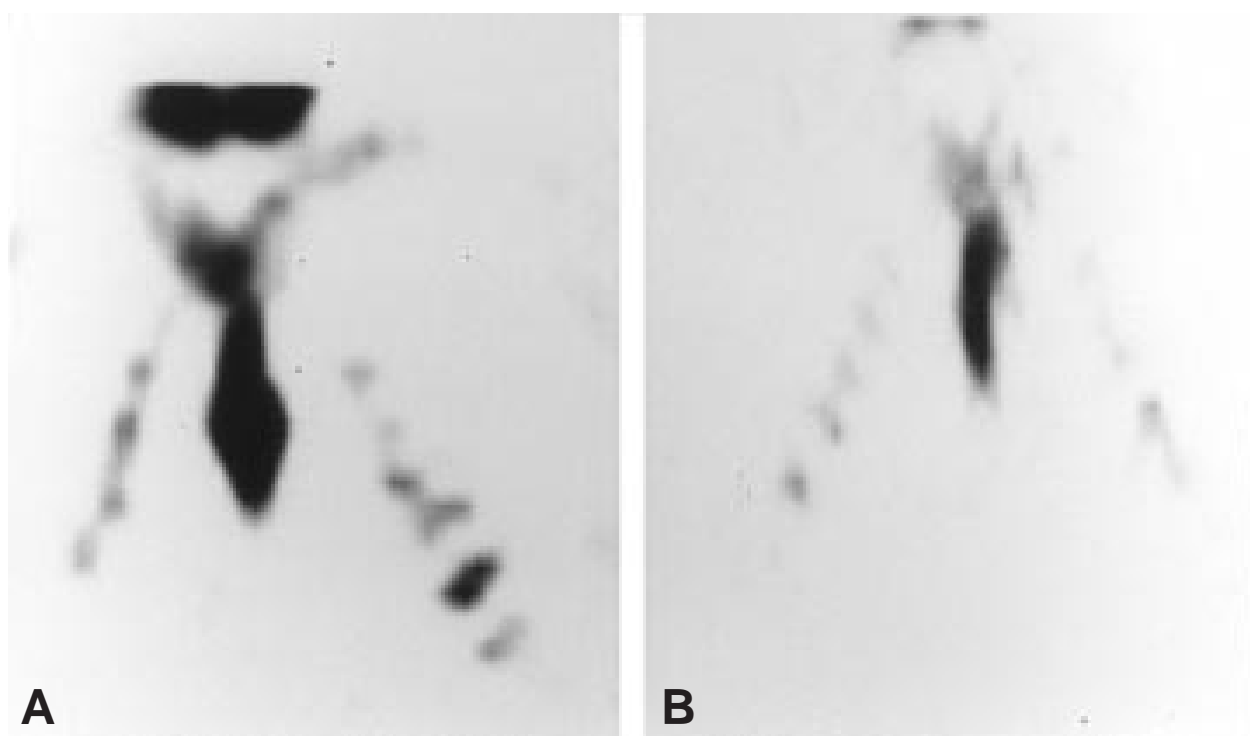

Fig 1. Representative coronal sections of technetium 99 methylene diphosphonate bone SPECT scans showing normal uptake in the sternum before the operation (A) and reduced uptake in the left hemisternum after the operation (B) with a pedicled ITA graft.

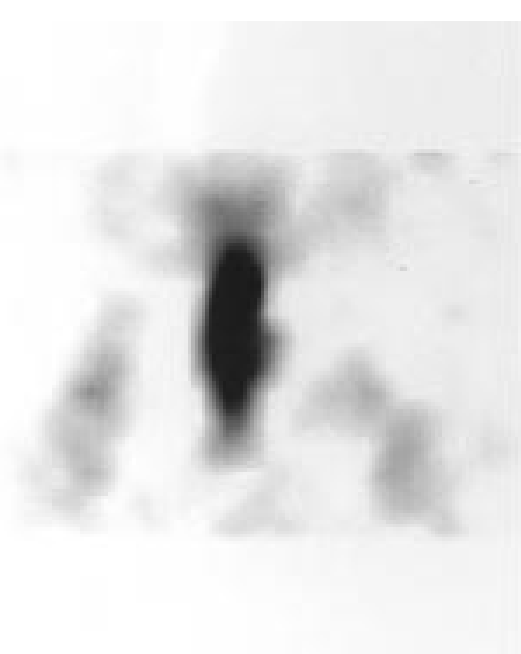

A

Fig 2. Representative coronal sections of technetium 99 methylene diphosphonate bone SPECT scans showing normal uptake in the sternum before the operation (A) and normal uptake in the left hemisternum after the operation (B) with a skeletonized ITA graft.

1 demonstrates baseline and follow-up coronal sections of the bone SPECT in a patient with a pedicled graft. Patients with skeletonized grafts had no significant alteration in sternal activity after the operation (Table III). Fig 2 shows a coronal bone SPECT in a patient with a skeletonized graft. Again, no significant difference was detected in the area evaluated between the left and right sides of the sternum in either group (Table III). Multivariable logistic regression analysis of preoperative and operative variables revealed only a pedicled ITA to be associated with a greater than $20 \%$ reduction in postoperative left-to-right sternal activity 
Table IV. Short-term follow-up

\begin{tabular}{lccc}
\hline Variables & $\begin{array}{c}\text { Skeletonized } \\
\text { group }(n=11)\end{array}$ & $\begin{array}{c}\text { Pedicled group } \\
(n=12)\end{array}$ & P value \\
\hline Hours intubated $^{*}$ & $20.41 \pm 17.8$ & $16.45 \pm 7.6$ & .5 \\
$\begin{array}{l}\text { Amount of bleeding } \\
\times 24 \text { hours }\end{array}$ & $464.12 \pm 439$ & $607.27 \pm 439$ & .3 \\
$\quad$ Time in ICU (h) & & & .22 \\
Time in hospital & $39 \pm 23.9$ & $54 \pm 33.6$ & .24 \\
$\quad($ days) & $5.9 \pm 1.7$ & $7.1 \pm 2.9$ & \\
CVA & 1 & &
\end{tabular}

$I C U$, Intensive care unit; $C V A$, cerebral vascular accident.

*Values are mean \pm standard deviation.

ratio $($ odds ratio $=100 ; 70 \%$ confidence limits $=22$ 465; $P=.002)$.

Short-term postoperative results are shown in Table IV. No significant differences could be shown between the groups with regard to intensive care unit and hospital stays, although these were consistently shorter in group I. Postoperative follow-up was performed at 3.1 \pm 1.2 months in group I and $2.8 \pm 1.1$ in group II $(P=$ .67). One death occurred in the skeletonized ITA group; it was caused by prolonged sepsis after a cerebral vascular accident, without mediastinitis. No deep wound infections occurred in either group. There were no significant differences in readmissions or superficial infections. Patients receiving a pedicled ITA graft had more overall sternal pain, but no difference could be found related to the intensity or characteristics of the pain.

\section{Comment}

Sternal complications after CABG range from chest discomfort and numbness in the sternum to mediastinitis. Such sternal complications have been associated with prolonged mechanical ventilation, increased cardiopulmonary bypass time, older age, and diabetes. ${ }^{7-12}$ Whether the use of an ITA graft contributes to these complications is controversial. ${ }^{7,9,11,12}$ Evidence is stronger that bilateral ITA grafts increase sternal complications. ${ }^{7,8,10,11}$ The effects of ITA harvest on the sternum are caused by devascularization of the sternum. ${ }^{4}$ Recently, it has been shown that the use of a skeletonized ITA is associated with a reduced rate of sternal infection and other sternal complications. . $^{3,13,14}$

The fact that the harvest of an ITA pedicle devascularizes the sternum is well established in experimental literature. Arnold, ${ }^{5}$ in a human cadaver study, established that the ITA is the major supply, if not the sole supply, to the ipsilateral sternum. Seyfer and coworkers ${ }^{6}$ used microspheres in rhesus monkeys to show that
Table V. Long-term follow-up

\begin{tabular}{lccc}
\hline Variables & $\begin{array}{c}\text { Skeletonized } \\
\text { group }(n=10)\end{array}$ & $\begin{array}{c}\text { Pedicled } \\
\text { group }(n=12)\end{array}$ & P value \\
\hline Deaths & 1 & 0 & .49 \\
Readmissions & 3 & 4 & .4 \\
Superficial infection & 1 & 3 & .32 \\
Chest pain & 3 & 7 & .046 \\
Numbness and tingling & 8 & 5 & .6 \\
Pain with breathing & 1 & 2 & .57 \\
Pain on palpation & 7 & 8 & .8 \\
\hline
\end{tabular}

harvest of a pedicled ITA results in $90 \%$ reduction of mean blood flow in the ipsilateral half of the sternum. ${ }^{6}$ When bilateral pedicled ITAs were harvested, the flow was drastically reduced to the entire sternum. ${ }^{6}$ Lust and colleagues ${ }^{15}$ used a porcine model and microspheres to show a 74\% reduction in blood flow to the ipsilateral hemisternum after ITA harvest. A drastic reduction in total sternal blood flow was demonstrated with bilateral ITA harvest. ${ }^{15}$ Parish and associates ${ }^{16}$ used a dog model in which they harvested bilateral ITAs, a pedicled ITA on one side and a skeletonized ITA on the other side. They used microspheres to demonstrate the reduced blood flow on the side of the sternum where the pedicled ITA was harvested.

Clinical data demonstrating devascularization of the sternum after ITA harvest are sparse. Carrier and coworkers ${ }^{17}$ studied 67 patients after cardiac operations using sternal bone scan tomography. They were able to show a reduction in blood flow to the sternum after a single ITA graft. They were also able to show that a double ITA harvest further reduces sternal blood flow. This article offers no details regarding the technique of ITA harvest. In contrast, Rivas and colleagues ${ }^{18}$ used conventional bone scan to evaluate sternal blood flow 7 days after CABG. Despite the use of pedicled ITA grafts, they could not find any difference in postoperative sternal flow between groups with no ITA graft, 1 ITA graft, or 2 ITA grafts.

Our study is the first study in human beings to compare flow in a hemisternum after a pedicled ITA versus a skeletonized ITA graft. It is also the first study to use a SPECT scan to evaluate vascularity of the sternum after ITA harvest. Our study was controlled by preoperative scans in each patient, which showed similar flow to each hemisternum in all patients. Further, since it is known that ITA harvest has a minimal effect on the contralateral hemisternum, ${ }^{4-6,15,16}$ it was valid to use the contralateral hemisternum as a control for the hemisternum in which the ITA was harvested. Our study showed a significant reduction of postoperative 
flow in the hemisternum in group II, in which a pedicled ITA was harvested. This could not be demonstrated in group I. As both groups were similar with respect to preoperative and operative variables, one could infer that the type of ITA harvest was responsible for this effect. This conclusion is supported by the fact that multiregression analysis, including all preoperative and operative variables, including diabetes, identified a pedicled ITA as the only factor associated with reduced postoperative blood flow in the ipsilateral hemisternum. This conclusion concurs with most experimental and clinical studies. The divergent results obtained by Rivas and coworkers ${ }^{18}$ may be due to the less sensitive technique used to detect reduced blood flow in their study, as well as a scan that was performed later in the postoperative course.

Previous studies have been able to demonstrate fewer sternal infections and less sternal discomfort after harvesting a skeletonized versus a pedicled ITA. ${ }^{3,13,14}$ Our study implies that patients undergoing harvest of a skeletonized ITA graft have less postoperative sternal discomfort than those having a pedicled ITA graft. It is the first study to demonstrate reduced postoperative sternal blood flow and increased postoperative sternal pain in the same population. However, our patient population is too small to allow definite conclusions as to whether these two factors are related. Further studies with a larger population are needed to confirm this finding.

Our study has a number of limitations. First, this is the first time that this method of scanning has been used to quantitate sternal blood flow in this manner. The rationale for the use of this scan is based on the fact that the blood supply to the bone, and the amount of osteoblastic activity, are the two major determinants of osseous localization of bone-seeking radiopharmaceuticals. In our patients, decreased bone uptake in the sternum reflects mainly reduced blood flow, since osteoblastic activity is expected to increase as part of the healing process after surgery. ${ }^{19}$ This form of scanning, with the use of ROI, has been used quantitatively in other parts of the body. ${ }^{20,21}$ Bone scanning has also previously been used to assess sternal vascularity. ${ }^{17,18}$ However, since this exact method has not previously been used, the level of its accuracy remains to be proven. Second, the postoperative scans were not done on the same postoperative day for each patient. Since crossover vascularity between the hemisternums may start within the first week after the operation, ${ }^{4,22}$ this may affect the results. Third, clinical follow-up of the patients did not occur at the same time after the operation, and this may influence the level of the patients' discomfort. Fourth, the population studied was small, and no deep wound infection occurred. As such, no inference can be made regarding the effect that acute sternal devascularization has on the incidence of postoperative mediastinitis.

Our study does not elucidate the mechanism of increased sternal ischemia found in group II versus group I. It may be either injury of small arterial channels or passive congestion due to decreased venous drainage. Further, the study gives no information concerning sternal vascularity after bilateral ITAs. Finally, on the basis of animal studies, we suppose that the sternal ischemia demonstrated here is temporary. We intend to study these patients later to verify this assumption.

With these limitations in mind, the following conclusions may be drawn:

1.Pedicled ITA harvest reduces the postoperative blood flow to the ipsilateral hemisternum.

2. This reduced blood flow is not present when a skeletonized ITA is harvested.

Recommendations. In patients at increased risk for sternal infections or in whom bilateral ITAs are to be used, use of the skeletonized ITA should be considered to reduce acute postoperative sternal ischemia.

We thank Sally Esakov for editorial assistance.

\section{REFERENCES}

1. Singh RN, Sosa JA, Green GE. Long-term fate of the internal mammary artery and saphenous vein grafts. J Thorac Cardiovasc Surg 1983;86:359-63.

2. Lytle BW, Loop FD, Cosgrove DM, Ratliff NB, Easley K, Taylor PC. Long-term (5-12 years) serial studies of internal mammary artery and saphenous vein grafts. J Thorac Cardiovasc Surg 1985; 89:248-58.

3. Galbut DL, Traad EA, Dorman MJ, et al. Seventeen-year experience with bilateral internal mammary artery bypass grafts. Ann Thorac Surg 1990;49:195-201.

4. Graeber GM. Harvesting of the internal mammary artery and the healing median sternotomy. Ann Thorac Surg 1992;53:7-8.

5. Arnold M. The surgical anatomy of sternal blood supply. J Thorac Cardiovasc Surg 1972;64;596-610.

6. Seyfer AE, Shriver CD, Miller TR, Graeber GM. Sternal blood flow after median sternotomy and mobilization of the internal mammary arteries. Surgery 1988;104:899-904.

7. Culliford AT, Cunningham JN Jr, Zeff RH, Isom OW, Teiko P, Spencer FC. Sternal and costochondral infections following open heart surgery: a review of 2,594 cases. J Thorac Cardiovasc Surg 1976;72:714-26

8. Grossi EA, Culliford AT, Kreiger KH, et al. A survey of 77 major infectious complications of median sternotomy: a review of 7,949 consecutive operative procedures. Ann Thorac Surg 1985; 40:214-23.

9. Grossi EA, Esposito R, Harris LJ, et al. Sternal wound infections 
and use of internal mammary artery grafts. J Thorac Cardiovasc Surg 1991;102:342-7.

10. Loop FD, Lytle BW, Cosgrove DM, et al. Sternal wound complications after isolated coronary bypass grafting: early and late mortality, morbidity, and cost of care. Ann Thorac Surg 1990;49:179-87.

11. Kouchoukos NT, Wareing TH, Murphy SF, Pelate C, Marshall WG Jr. Risks of bilateral internal mammary artery bypass grafting. Ann Thorac Surg 1990;49:210-9.

12. Hazelrigg SR, Wellons HA Jr, Schneider JA, Kolm P. Wound complications after median sternotomy: relationship to internal mammary grafting. J Thorac Cardiovasc Surg 1989;98:1096-9.

13. Mills NL, Bringaze WL III. Preparation of the internal mammary artery graft: Which is the best method? J Thorac Cardiovasc Surg 1989;98:73-9.

14. Wimmer-Greinecker G, Yosseef-Hakimi M, Rinne T, et al. Effect of internal thoracic artery preparation techniques on blood loss, lung function and postoperative pain. Ann Thorac Surg. In press.

15. Lust RM, Kasagi Y, Chapman SF, Morrison RF, Sun YS, Chitwood WR. Influence of unilateral and bilateral internal mammary takedown on sternal blood flow (abstract 1946). Circulation 1987;76(pt 2, Suppl):IV488.
16. Parish MA, Asai T, Grossi EA, et al. The effects of different techniques of internal mammary artery harvesting on sternal blood flow. J Thorac Cardiovasc Surg 1992;104:1303-7.

17. Carrier M, Gregoire J, Tronc F, Cartier R, Leclerc Y, Pelletier LC. Effect of internal mammary artery dissection on sternal vascularization. Ann Thorac Surg 1992;53:115-9.

18. Rivas LF, Hawkins T, Morritt GN, Behl RP, Griffin SC, Brown AH. Radiopharmaceutical uptake as a marker of sternal blood supply following internal mammary artery harvesting. Cardiovasc Surg 1994;2:203-6.

19. Fogelman I. Skeletal uptake of diphosphonate: a review. Eur J Nucl Med 1980;5:473-6.

20. Naito M, Ogata K, Moriguchi H. Quantitative bone scanning of the hip: comparison between the perfusion and static phases. Int Orthop 1996;20:311-4.

21. Verlooy H, Mortelmans L, Vleugels S, De Roo M. Quantitative scintigraphy of the sacroiliac joints. Clin Imaging 1992;16:230-3.

22. Lust RM, Kasagi Y, Chapman SF, et al. Residual sternal ischemia following median sternotomy repair despite retention of one intact internal mammary artery (abstract 1902). Circulation 1988; 78(pt 2, Suppl):II477. 